\title{
ALBAY EMERGENCY RESPONSE AND REPORT TOOL (ALERRT)
}

\author{
Elmer Figuracion, Thelma Palaoag, Dennis Ignacio and Mary Jane \\ Doblon
}

\author{
College of Information Technology and Computer Science, University of the \\ Cordilleras, Baguio City, Philippines, 2600 \\ ecfiguracioneyahoo.com \\ tpalaoag@gmail.com \\ denzignacio@yahoo.com \\ jhainedoblon@yahoo.com
}

\begin{abstract}
Resilient public alert and warning tools are essential to save lives and protect property during times of national, regional, and local emergencies. Nowadays, immediate emergency alerts became one of the priority in both national and local government. The Provincial Government of Albay is geared towards becoming the most liveable province of the Philippines, which means that it would be known for good education, good healthcare and good environment where people are healthy, happy, employed and lives to their full potential. To achieve this goal, disaster risk reduction and climate change adaptation must be anchored well so as to move to its destination of shared socioeconomic advancement. Supporting this vision, this study focuses on the design and development of a mobile based Albay Emergency Reporting and Response Tool (ALERRT). It is a mobile based resilient form of emergency alert notification that aids the concerned citizens of any emergencies, accidents and concerns that require immediate response from the government sector concerned.

In order to materialize this project, Featured-driven (FDD) methodology was used. Likewise, opinions from different strata of society were solicited along the areas on social awareness, readiness to respond and willingness to use a mobile application to report an incident or emergencies. With $92.5 \%$ of the respondent who is willing to report an incidents or emergencies, this application paved way to a better agency response and levering the people to use IT solutions to become resilient in times of emergencies. It can be used to report on emergencies ranging from fires to typhoon-related incidents, vehicular accidents with casualties, health-related concerns (e.g. unidentified person suffering from heart attack), community related incidents \& concerns, and any other occurrences which requires immediate and concrete response from the concerned agencies. Having such resilient form of emergency alert notification like ALERRT is deemed necessary for a disaster prone places like Albay.
\end{abstract}

\section{KEYWORDS}

Emergency response, Disaster management, Incident report, Incident mapping, Mobile Application

\section{INTRODUCTION}

All throughout the year, there could never be a chance that we could be spared from any disasters or occurrences like floods and storms which are the most frequently occurring hazards. Aside

Natarajan Meghanathan et al. (Eds) : NETCOM, NCS, WiMoNe, GRAPH-HOC, SPM, CSEIT - 2016 pp. 161-177, 2016. @ CS \& IT-CSCP 2016

DOI : $10.5121 /$ csit.2016.61514 
from the mentioned natural calamities, the country also experiences human-induced disasters brought about or influenced by political or socio-economic factors, among others. Violence, traffic hazards, road accidents, broken pipes or electric wires for instance has caused public anxiety, lost of lives, destruction of properties, and living discomforts.

This mobile application- Albay Emergency Reporting and Response Tool (ALERRT) is a tool that seeks to encourage the people to become proactive members of the community by increasing their awareness thereby improving resilience and decreasing vulnerabilities. This will provide the citizens to have an easy means of reporting any incidents (emergencies, accidents or concerns) requiring response from any local or national government units, allow citizens to have detailed documentation of the event (image/video capture), allow concerned government sector to act based on reported scenario, and citizens can track down government actions (i.e. action taken on the reported vehicular accident). Furthermore, the system can resolve several issues which include but not limited to slow response of concerned government agencies, poor participation and responsiveness from the community, and unresolved cases of incidents.

\subsection{Survey Questionnaires}

In order to gather enough data for the system, opinions from different strata of society were solicited through a questionnaire. The respondents include $10 \mathrm{High}$ School students, 10 College students, 10 Professionals, and 10 members of the households whose age bracket is reflected in Table 1; they were randomly chosen by the respondents. The survey questionnaire includes questions on their social awareness, readiness to respond, and also their willingness to use a mobile application in reporting incidents.

Table 1. Respondent's Demographics

\begin{tabular}{|l|c|c|c|c|}
\hline Age Bracket & High School & College & Professional & Household \\
\hline 16 below & 10 & & & \\
\hline 17- 24 yrs.old & & 10 & 4 & \\
\hline 25- 34 yrs.old & & & 5 & 3 \\
\hline 35-44 yrs.old & & & & 2 \\
\hline $45-54$ yrs.old & & & & \\
\hline 55 yrs.old above & & & & \\
\hline
\end{tabular}

The result of the survey done through questionnaire revealed that 37 respondents or $92.5 \%$ are willing to respond to incidents. See table 2 below.

Table 2. Willingness to Report Emergency Situations

\begin{tabular}{|l|c|c|}
\hline Educational Attainment/Status & Yes & No \\
\hline High School & 10 & 0 \\
\hline College & 9 & 1 \\
\hline Professional & 10 & 0 \\
\hline Household & 8 & 2 \\
\hline TOTAL & $\mathbf{3 7}$ & $\mathbf{3}$ \\
\hline
\end{tabular}


Social awareness was also asked to the respondents, this includes their knowledge of the location of police stations, clinics and hospitals, and barangay halls within their vicinity. Results show that $82.5 \%$ of the respondents know the location of police stations, $95 \%$ in hospitals and clinics, and $90 \%$ in barangay halls nearby.

However, most of the respondents are not aware of the emergency hotlines of police, hospitals, fire dept, etc. in their area. Table 3 reveals the result.

Table 3. Awareness of Emergency Hotlines

\begin{tabular}{|l|c|c|}
\hline Educational Attainment/Status & Yes & No \\
\hline High School & 1 & 9 \\
\hline College & 0 & 10 \\
\hline Professional & 2 & 8 \\
\hline Household & 3 & 7 \\
\hline TOTAL & $\mathbf{6}$ & $\mathbf{3 4}$ \\
\hline
\end{tabular}

The survey likewise revealed that majority of the respondents are smart phone users, and almost all are interested to use a mobile application in reporting an incident; and when asked to rank the features that they would like to see in the application, $57.5 \%$ would like an app that would send a text message to report the incident (see table 4 below).

Table 4. Features of the mobile app to be made available

\begin{tabular}{|l|c|c|c|c|c|c|}
\hline $\begin{array}{l}\text { Mobile App } \\
\text { Feature }\end{array}$ & $\begin{array}{c}\text { High } \\
\text { School }\end{array}$ & College & Professional & Household & Total & Rank \\
\hline $\begin{array}{l}\text { Text report of } \\
\text { incident }\end{array}$ & 5 & 8 & 6 & 4 & 23 & 1 \\
\hline $\begin{array}{l}\text { Documentation of } \\
\text { event(image/video) }\end{array}$ & 4 & 5 & 6 & 2 & 17 & 2 \\
\hline $\begin{array}{l}\text { Allow concerned } \\
\text { sector to act based } \\
\text { on the report } \\
\text { scenario }\end{array}$ & 1 & 3 & 3 & 1 & 8 & 4 \\
\hline $\begin{array}{l}\text { Allow viewing of } \\
\text { feedback, response, } \\
\text { and action taken for } \\
\text { the incident }\end{array}$ & 2 & 5 & 4 & 3 & 14 & 3 \\
\hline
\end{tabular}

\subsection{Interview}

An interview was conducted to a personnel of Albay Health Emergency Management (AHEM) and Bureau of Fire Protection (BFP) so as to be acquainted on how emergency responses are done by their agencies.

An interview was conducted to the following personnel of two agencies: 
1. Mr. Eduard E. Gandul Jr.- a registered Nurse and midwife, certified medical responder for almost 5 years, and an emergency medical technician. He is currently connected with Bicol Regional Training and Teaching Hospital (BRTTH-HEMS)/ Albay Health Emergency Management (AHEM).

2. Gelacio Molato Jr., BFP - assigned at Bureau of Fire Protection Tabaco City.

Questions include the procedure when receiving reports of incidents (fire or any emergencyrelated incidents), emergency measures, and their suggestions to the study being conducted. According to them, they follow a certain protocol in reporting and receiving incident reports from various sources; however, the very common source is through telephone calls. In receiving reports, they follow the "NOIPOITOI" format which stands for: Name of Incident-Place of Incident-Time of Incident. The communication officer receives the information reported by the caller and transmits it to the rescuers/ agencies concerned.

The data collected from the interview aided the researchers in conceptualizing the format of the report needed so as to post in the wall of the various agencies linked to the application.

\section{REVIEW OF RELATED LITERATURE}

The "New Media" has been in many ways assisted the dissemination of any news, information and data to the people. Whether it is about, health, disaster or emergency situation, it has in many ways made the life of the people accessible, easy, and updated. The following studies present the role of social media and or wireless reporting system in public health, disaster management, and crime management.

Dong (2015) in his capstone study on "Social Media in Public Health Organizations: A Case Study of Social Media Use in the Minnesota Department of Health" mentioned that mobile communication or Smart phone penetration brings a new range of possibilities for public health promotion, as the demographic is getting more and more comfortable with mobile news feeding. He further mentioned that the MDH (Minnesota Department of Health) mainly uses Twitter to disseminate news and update about the agency's work and events; uses Facebook to personalize the organization by employing images and storytelling in content; and uses YouTube for public education and to support public health campaign work. ${ }^{1}$ Related to Dong's study is Owen, Daniel's (2013) thesis entitled "Citizen Photojournalism: Motivations for Photographing a Natural Disaster and Sharing the Photos on the Web" shared that the citizen photojournalists inform an audience with their pictures and then they interact with a community with their pictures, they would like to inform the audience about the event of any disaster. Informing an audience coincides with sharing the photos online because it is the easiest way to publish their photos to inform people. Social media Web sites such as Flickr, Facebook and Twitter are hosts for the online communities in which the citizen photojournalists belong. ${ }^{2}$

Barbeau (2007) in his paper "Wireless Emergency Reporting System" presented a method of providing emergency related information to and from a centralized location over a wireless network. The method utilizes cellular phones in emergency communications and entails two embodiments that employ location aware technologies, in portable form, in security applications. One embodiment serves as a modern high-tech "neighborhood watch," enabling law enforcement access to the many "eyes and ears" of the public simultaneously via available cell phones. Cell phones with embedded digital cameras allow the instant capture and remote submission of suspicious circumstances to law enforcement through pictures or video. ${ }^{3}$ 
Mobile Technology has aided the reporting of various incidents which aims to resolve the sloppy communication and action of the agencies concerned. The following studies ranging from disaster response, health related issues, crime related incident, and others, cited several functionalities that will prove the beneficiality of a reporting and response tool.

Fajardo, et.al (2010) developed the "A Mobile Disaster Management System Using the Android Technology" or simple called MyDisasterDroid to determine the optimum route along different geographical locations that the volunteers and rescuers need to take in order to serve the most number of people and provide maximum coverage of the area in the shortest possible time. ${ }^{4}$

Tamboli, et. al (2013) in his study "Incident Reporting System Using GIS" presented a paper about integrated application-software which will be used to report an incident or accident immediately and also keep the log of activities which in turn helping public and the authorities to deal with problems and emergencies. Among the applications of the system include a notification of any incident to concerning department, thus the concerned authorities can respond quickly and in an efficient way to solve the problem; it is also used to navigate the response team in minimum possible time; as it keeps the log of activities so it can also be used to maintain log of incidents for further investigation, and this application will help to handle any kind of incident which requires help in a hassle free manner and will also analyze the incident to be reduced. In summary, this application will provide a communication medium for the public to indicate to the respective authorities about the emergencies or incidents identified. This is a very useful real-time application for time-critical incidents. ${ }^{5}$

Eguchi, R. (2008) is his prepared paper entitled "The Application of Remote Sensing Technologies for Disaster Management" focused on the integration of remote sensing technologies in all aspects of disaster management, i.e., disaster preparedness, mitigation, response and recovery. In order to demonstrate their efficacy in these four areas, cases histories and examples from recent disasters, including the Marmara, Turkey earthquake, the Bam, Iran earthquake, and the Indian Ocean earthquake and tsunami are discussed. Finally, the paper ends with a view towards the future. What new developments can be expected in technology development and implementation, and what future challenges must be overcome to realize broader application of these technologies in future disasters. ${ }^{6}$

A case study presented by Gupta, Preeti, et.al (2011) dealt on "Disaster Management in Flash Floods in Leh" was based on the authors' own experience of managing a natural disaster caused by the flash floods. The paper presents a firsthand description of a disaster and its prompt management. The data was collected from the records of the district civil administration, the civil hospital, and the Army Hospital, Leh. The approach used was both quantitative as well as qualitative. It included data collection from the primary sources of the district collectorate, interviews with the district civil administration and army officials who organized rescue operations, restoration of communication, and transport, mass casualty management, and informal discussions with local residents. In here, the researchers emphasized the importance of readiness not just in the health sector, disaster management sector, but also with the communication and transmission aspect. ${ }^{7}$

K Nakajima, et. al (2016) developed "A Web-Based Incident Reporting System and Multidisciplinary Collaborative Projects for Patient Safety in a Japanese Hospital" which is currently recognized as a useful tool for patient safety in individual hospitals as well as at the national level. The use of a computerized system in limited settings such as intensive care units succeeded in involving physicians in reporting to a greater extent, where they accounted for more than $20 \%$ of the total number of reports. Reported incidents have led professional groups to take action, including making recommendations for restrictions on storage areas for high risk drugs and the establishment of a Department of Clinical Engineering for the centralized management of 
medical devices; as well as reporting incidents and a faster response to problems brought to light as a result of such reporting - which were the barriers that we faced in introducing the patient safety programs, can be resolved by the web-based incident reporting system which streamlines the process of reporting and information sharing. ${ }^{8}$

In the study entitled "Use of Mobile Phones in an Emergency Reporting System for Infectious Disease Surveillance" conducted by Yang, C. et.al (2010), the result indicates that the mobile phone reporting system helped restore the reporting capacity of health-care agencies in earthquake-affected areas. The drop in the number of cases reported might have been caused by two factors: the rate of unreported cases increased because doctors were flooded with patients after the earthquake; and the occurrence of infectious disease in some areas was possibly lower than in past years due to the stringent disease prevention. Last, whenever possible, mobile phones with global positioning system (GPS) capacity should be used. The reporting system can be programmed to attach coordinate data to each text message automatically. This could help us track the disease in a spatial resolution higher than the township level. And control measures adopted by Chinese authorities after the earthquake. ${ }^{9}$

Yunus (2006) in his thesis "Web Based Multi-Participant Spatial Data Entry in Crime Mapping" designed a crime mapping system in order to produce data along with a web based data entry methodology. The emphasis of the study is to convey some new improvements for effective and accurate geocoding of point based crime incidents, offenders and victim's data. The study establishes a server side Web architecture that provides map visualization.In summary, this study can be a prototype for online crime mapping in tactical crime analysis. ${ }^{10}$

\section{THE SYSTEM}

\subsection{Conceptual Model}

To fully understand the main functions of the system, a use case diagram was used to illustrate the main activities of the stakeholders as shown in Figure 1.

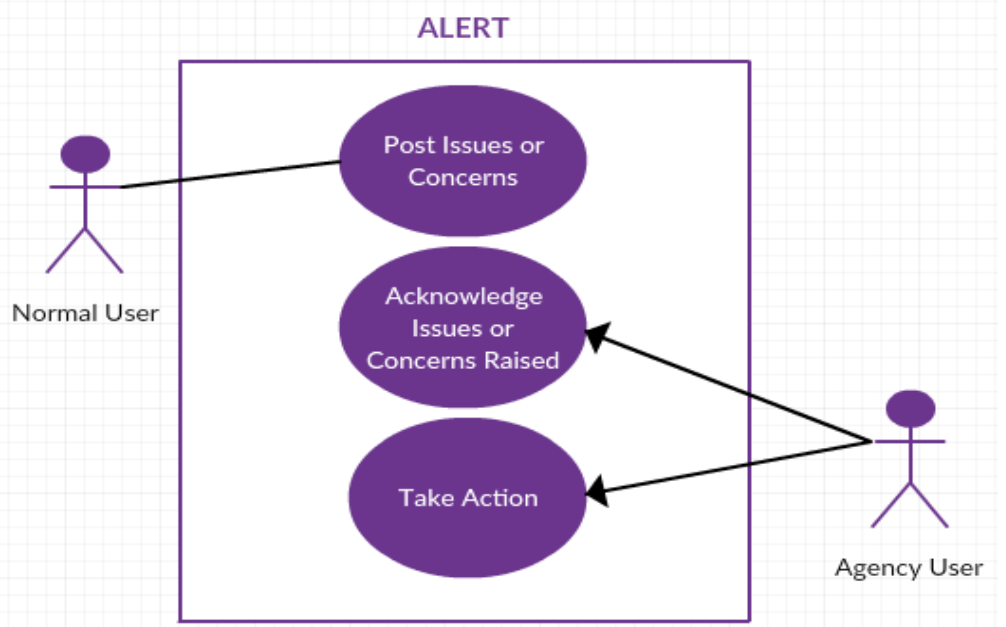

Figure 1. ALERRT System Overview

In general, the ALERRT system involves two important users as shown in figure 1: 1. Normal User 2. Agency User. The normal user is the one involved in raising issues and concerns that requires the agency's attention. Once a certain issues/concerns are raised, then it is the responsibility of the agency user to acknowledge the post and take proper action. In summary, 
the objective is to let the preferred agency know the issues/concerns so that proper action can be carried over by the concerned agency.

\subsection{Database Design}

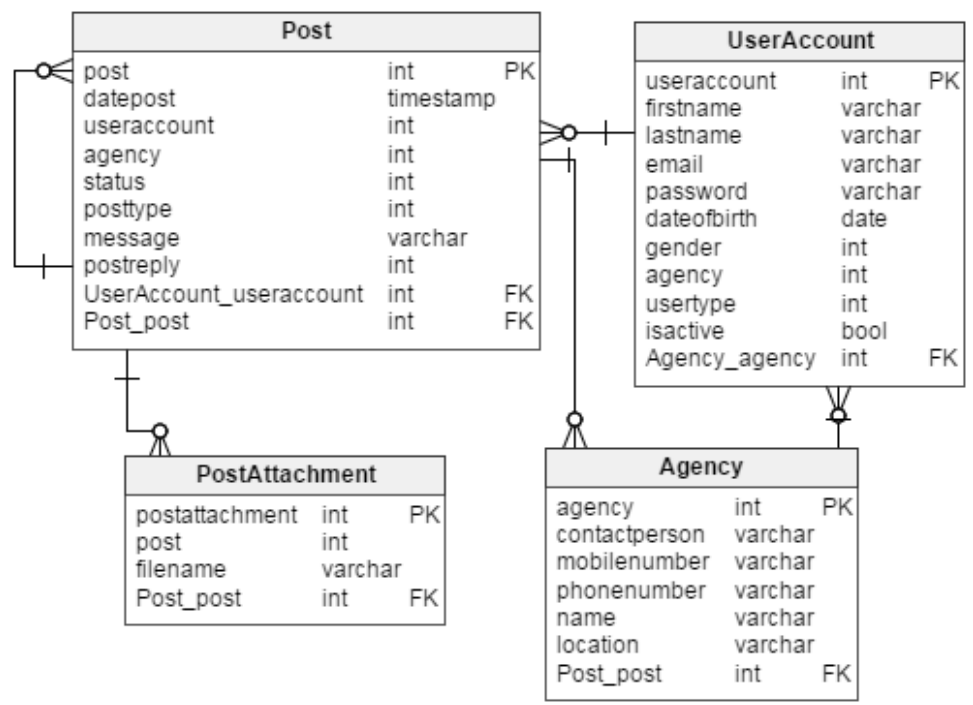

Figure 2. ER Diagram of ALERRT

There are four tables used in the ALERRT system as depicted in Figure 2. Below is the summary.

1. UserAccount - holds the records for ALERRT users. User's could be of the following types: a. normal user b. agency user c. admin user. A Normal user is limited in posting issues/concerns,; agency users are entitled to respond and take action to any issues/concerns raised by the normal user; and lastly the admin user is capable of maintaining the agencies and user accounts. The UserAccount table is linked to Agency table if the specific user is a representative of an agency.

2. Agency - holds records of registered agencies within the ALERRT system. Information in this table includes the contact person, mobile and phone number and the name of the agency and its location.

3. Posts - where all issues/concerns raised by user's or any public announcements by agencies are recorded. Posts are linked to the user who created the post, but is optionally connected to an agency. Only those posts which require the agency's attention are connected to agency. These kinds of posts are maintained in the status information for monitoring purposes (e.g. to track down what happens to the issues/concerns raised and how the agency respond to it). Lastly, each post is linked to itself; this signifies the replies made to a certain post.

4. PostAttachment - A post can optionally have picture attachments. This table handles the physical location of the image on the server for a certain post.

\subsection{Data Instances}

Succeeding figures below show sample data instances for ALERRT tables. 


\section{A. Agency}

\begin{tabular}{|l|l|l|l|l|l|}
\hline agency & contactperson & mobilenumber & phonenumber & name & location \\
\hline 1 & JUAN TAMAD & 09068240337 & 4800852 & BFP TABACO & TABACO \\
2 & PEDRO PENDUKO & 0906823123 & 4802334 & PSO LEGAZPI & LEGAZPI \\
3 & PEPITO MANALOTO & 0908123454 & 8201234 & BRTTH & LEGAZPI \\
4 & PETER PARKER & 4801234 & 090712345 & LCWD & LEGAZPI \\
\hline
\end{tabular}

Figure 3.1 Agency's Sample Data

The AGENCY table holds the basic information intended for agencies as depicted on Figure 3.1. Below is the summary of the fields used:

\begin{tabular}{|l|l|}
\hline Fields & Description \\
\hline Agency & Primary Key \\
\hline ContactPerson & The point person for the agency \\
\hline MobileNumber & Agency's mobile number \\
\hline PhoneNumber & Agency's phone number \\
\hline Name & Name of the agency \\
\hline Location & City Location of the Agency \\
\hline
\end{tabular}

\section{B. UserAccount}

\begin{tabular}{|l|l|l|l|l|l|l|l|l|l|}
\hline useraccount & firstname & lastname & email & password & dateofbirth & gender & agency & usertype & isactive \\
\hline 1 & Elmer & Figuracion & ecf@alert.com & ecf & $2001-01-01$ & 1 & & 1 & 1 \\
2 & Dennis & Ignacio & dennis@yahoo.com & dennis & $2001-01-01$ & 1 & 2 & 2 & 1 \\
3 & Jane & Doblon & jane@yahoo.com & jane & $1981-03-24$ & 2 & & 3 & 1 \\
4 & Juan & Tamad & Tamad & juan & $1945-08-25$ & 1 & 4 & 2 & 1 \\
5 & Maria & Makiling & maria@yahoo.com & maria & $1958-12-28$ & 2 & & 3 & 1 \\
\hline
\end{tabular}

Figure 3.2 UserAccount' Sample Data

The USERACCOUNT table holds the record of all the ALERRT's users. Below is the summarized field:

\begin{tabular}{|l|l|}
\hline Fields & Description \\
\hline Firstname & User's firstname \\
\hline Lastname & User's lastname \\
\hline Email & $\begin{array}{l}\text { Email Address used for login to } \\
\text { ALERT }\end{array}$ \\
\hline Password & Password used for login to ALERT \\
\hline DateOfBirth & User's date of birth \\
\hline Gender & Gender 1. Male 2. Female \\
\hline Agency & $\begin{array}{l}\text { Assigned with Agency PK when } \\
\text { user is linked to an agency, } \\
\text { otherwise it can be NULL }\end{array}$ \\
\hline UserType & $\begin{array}{l}\text { Type of user 1. Admin User 2. } \\
\text { Agency User 3. Normal User }\end{array}$ \\
\hline IsActive & \begin{tabular}{l} 
Signifies if user is active or not \\
\hline
\end{tabular} \\
\hline
\end{tabular}




\section{Post}

\begin{tabular}{|l|l|l|l|l|l|l|}
\hline post & datepost & message & agency & status & useraccount & postreply \\
\hline 42 & $2016-05-02$ 05:07:35 & Fire @ panal tabaco near st gregory & 1 & 1 & 3 & \\
43 & $2016-05-02$ 05:13:35 & Bridge under repair near Aquinas & & 0 & 2 & \\
44 & $2016-05-02$ 05:29:11 & No water supply since yesterday. & 2 & 3 & 3 & \\
45 & $2016-05-02$ 06:18:49 & Coordinating now to Bureu of Fire & & 0 & 2 & 44 \\
46 & $2016-05-02$ 06:21:34 & Fire truck now deployed for temporary & & 0 & 2 & 44 \\
47 & $2016-05-02$ 09:54:01 & Wakeup this morning and noticed & 4 & 1 & 5 & \\
48 & $2016-05-02$ 10:11:59 & Tricycle with plate number XFF1234 & 2 & 1 & 3 & \\
49 & $2016-05-02$ 10:48:52 & Same here @tahao road & & 0 & 3 & 47 \\
\hline \hline
\end{tabular}

Figure 3.3 POST's Sample Data

POSTS table records any issues/concerns raised and its replies by ALERRT's users. Below is the Summarized definition of the POST fields.

\begin{tabular}{|l|l|}
\hline Fields & Description \\
\hline Post & Primary Key \\
\hline DatePost & Date/Time of post \\
\hline Message & Text Description of the post \\
\hline Agency & $\begin{array}{l}\text { Intended agency. Linked to Agency } \\
\text { table }\end{array}$ \\
\hline Status & $\begin{array}{l}\text { Post Status which has the following } \\
\text { values 1. Public Information (when } \\
\text { post is for general public such as } \\
\text { announcements, advisory, etc) 2. } \\
\text { Reported(means the post is } \\
\text { intended to a specific agency and } \\
\text { its now flag as reported) 3. } \\
\text { Acknowledge (when post is } \\
\text { received by agency and raised } \\
\text { issues/concerned is now being } \\
\text { examined) 4. Action Taken (when } \\
\text { posts is already taking care of) }\end{array}$ \\
\hline UserAccount & The user who created the post \\
\hline PostReply & A reply to an existing post \\
\hline
\end{tabular}

\section{PostAttachment}

\begin{tabular}{|l|l|l|}
\hline postattachment & post & filename \\
\hline 15 & 42 & 50 ecdbdc-d7e6-4cf8-9cbf-f0ac1e8f8fb7.jpg \\
16 & 44 & cba099f2-8ca0-49e5-a4b7-2c0d2ef2ec34.jpg \\
\hline
\end{tabular}

Figure 4. POSTATTACHMENT's Sample Data

The POSTATTACHMENT table records all the images attached to a post. Below is the field definition:

\begin{tabular}{|l|l|}
\hline Fields & Description \\
\hline PostAttachment & Primary Key \\
\hline Post & Foreign Key to POST table \\
\hline Filename & File location of the image \\
\hline
\end{tabular}




\subsection{Sample Screenshots}

The ALERRT comprises three main users: normal user, agency user and an admin user. Each has its own purpose in maintaining the flow of information that goes within the ALERRT system. Below summarizes each user and their functions in the system.

\section{A. Normal User}

\section{Sign Up}

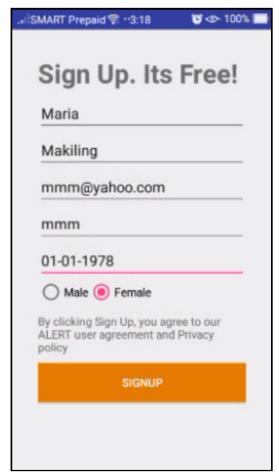

Figure 5. Sign Up

Signing up to ALERRT is the first step required to be involved in the system. Figure 5 shows the required information when signing up. The most important piece of information here is the email address. This is unique from the entire system and user won't be able to register if email is already in use.

\section{Post Issues/Concerns}

To post an issues or a concern, users need to be logged in first (1). Next is to press the write post button on top level highlighted on (2). This will take the user to (3) a screen. A post is by default intended for public information, but if the post requires agency attention, then pressing the $>$ besides "Attention: <Agency Name>" which will be taken to another screen where user can choose an agency. To attach an image to a post, the camera button lets the user choose an existing image from the phone. User can then describe the issues/concerns by typing some text and hitting the tick mark button to finally commit the post. This will lead to (4) where post written is available on the public wall.
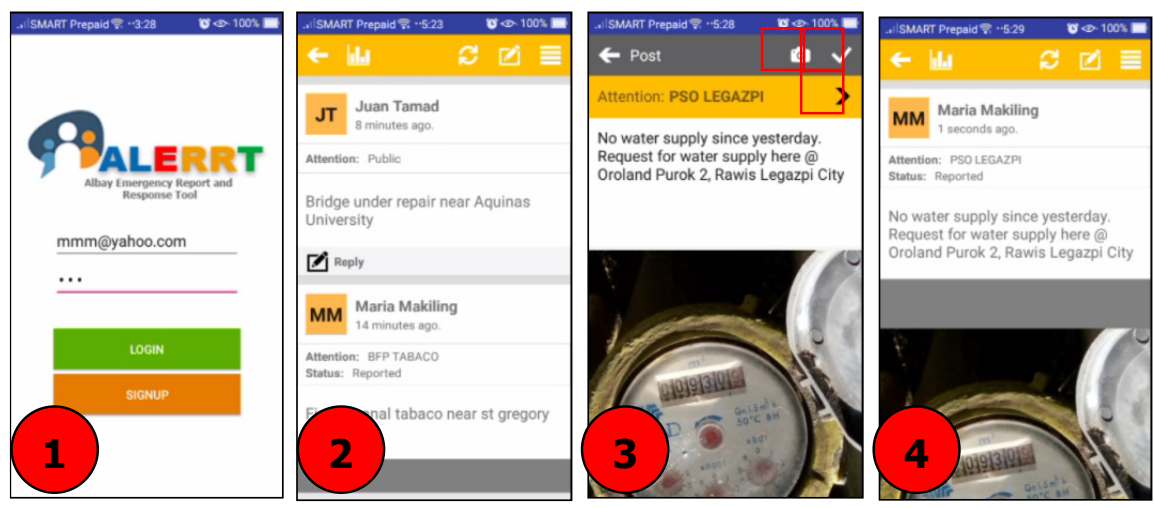

Figure 6. Post Issues and Concerns 


\section{Call Agency}
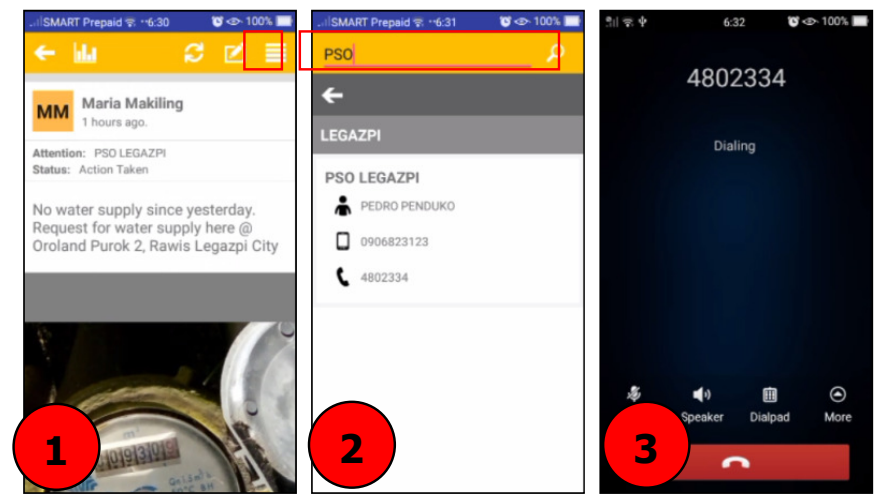

Figure 7. Contact Agency

ALERRT manages lists of registered agencies together with their respective contact numbers. This gives the capacity for all ALERRT users to contact the agency's representative directly. To invoke a call, from step (1) on the figure, tap the list icon. This will take every user to a screen showing all the registered agencies. Next is to search for the target agency as highlighted in step (2). To initiate a call, tap the mobile/phone icon which will open up (3) screen showing an ongoing call.

\section{B. Agency User}

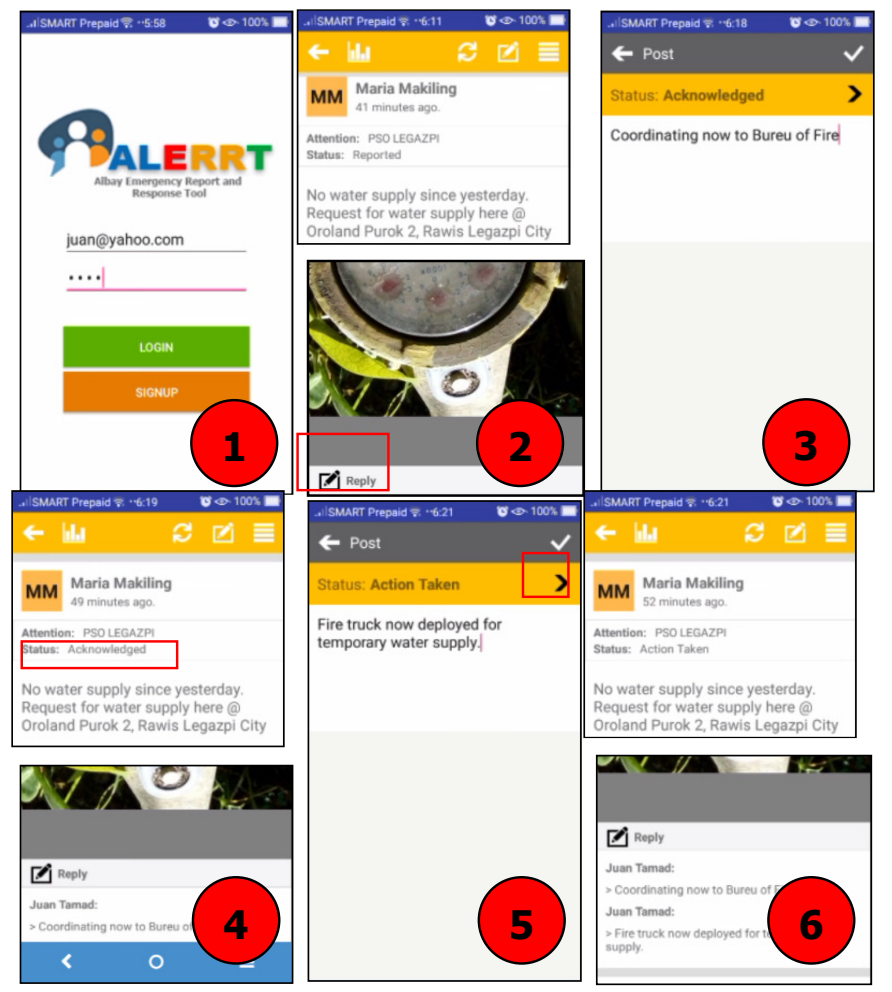

Figure 8. Agency User Respond to Post 
The Agency user's main purpose on ALERRT system is to track down issues/concerns raised against its agency and to take action based from post. To do this, agency user needs to be logged as depicted on (1). Next is to find the post that requires attention (2) and tapping the reply button. On (3) screen, the $>$ button on the right side of "Status:<Status Name $>$ " can be set to "Acknowledged". Preferably, this is the status that needs to be set by the agency once a post is received. This indicates that the post is being taken care of and the issues/concerns raised are now being examined. Screen (4) shows that the reply is reflected on the original post and the post status is now changed to "Acknowledged". Lastly, once the post is resolved, the agency user on (5) can now set the status to "Action Taken" including the text summary of the action being done. This is then reflected on the original post as show on screen (6).

\section{Admin User}

The Admin user maintains the list of registered agencies within the system as well as assigns a registered user to an agency. The screens below show the details of these functions.

\section{Register a new Agency}
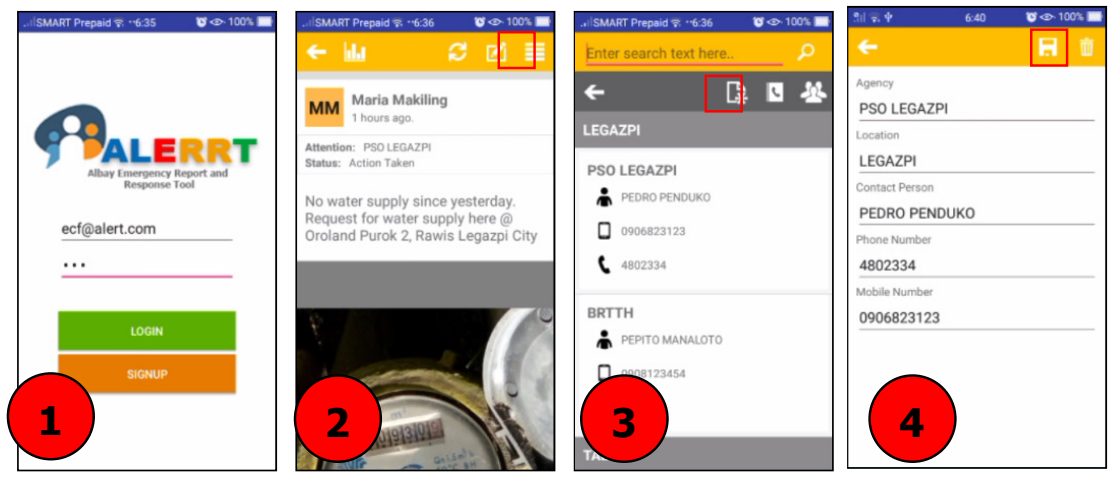

Figure 9. Register a new agency

After being logged in as shown on step 1, an admin user can then tap the list button (highlighted on step 2) to access the list of agencies and users. By default the list of agencies are listed. Now to register a new agency, tap the new button on step 2. This will open up the step 4 asking for agency information. Finally, by tapping the save button on step 4 it commits the new agency record.

\section{Assign user as agency representative}
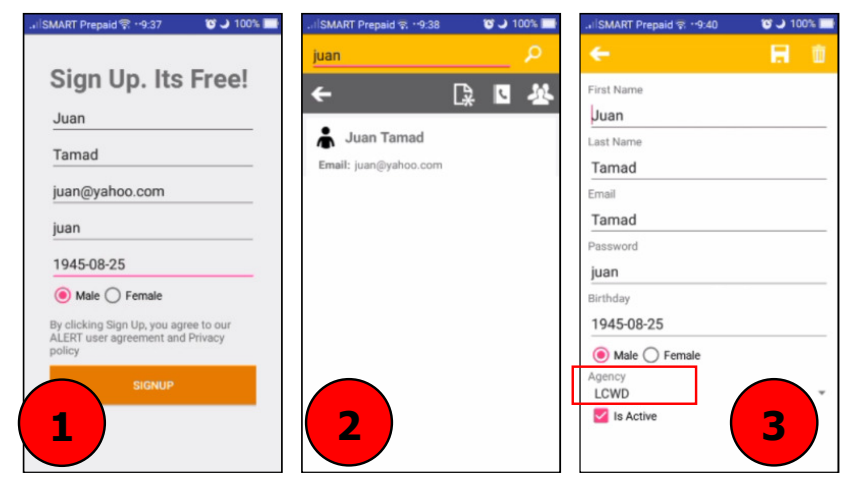

Figure 10. Assign user as agency representative 
Every agency needs to have a representative, which is called the agency user. This user needs to register first as normal user (1); and to become an agency user, he/she needs to contact the admin user to flag its account as agency representative. Step 2 shows the screen of admin user where it filters a certain user. Tapping the target user will show screen 3 , where user can then assign the preferred agency.

\section{DATA OPTIMIZATION}

The key concept of this study is about data optimization- that is getting information from a post and carries a necessary action to resolve the issues. Data optimization is an important aspect in database management in particular and in data warehouse management in general. It is most commonly known to be a non-specific technique used by several applications in fetching data from a data sources so that the data could use in data view tools and applications such as those used in statistical reporting. ${ }^{11}$

Any information posted by the user is significant in understanding the most common issues and concerns raised by a user, so as to aid the agencies for better understanding on what steps to be taken- to limit, if not to eradicate such concerns. Information carried on the post is of advantage to the agency to understand future concerns and to respond to it smoothly, the next time it happens again. The data collected from the post can be of great use in establishing connection to the constituents, raise awareness of event happening on the environment, and objectively encourage citizens to become proactive in common issues around them. The ALERRT system encourages not only the agency to become a good responder but also raises awareness to its users to become concerned citizens who are willing to assist when needed.

To aid the analysis of data, the ALERRT has three major reports that provide the overview of the data collected. As shown in Figure 11 below, the report can be accessed by clicking the chart icon on screen 1 .

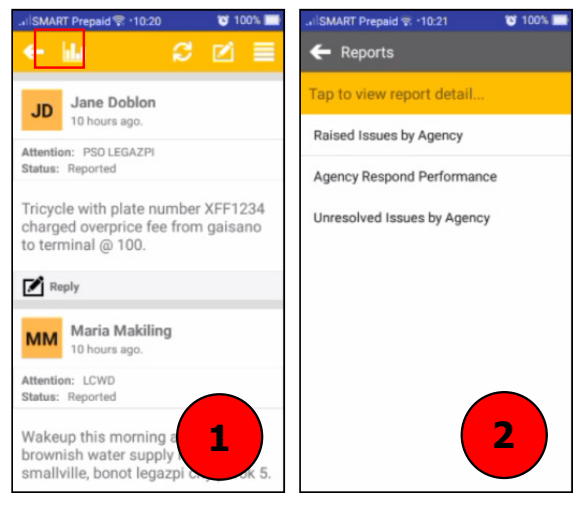

Figure 11. ALERT's reports 


\section{Raised Issues by Agency}
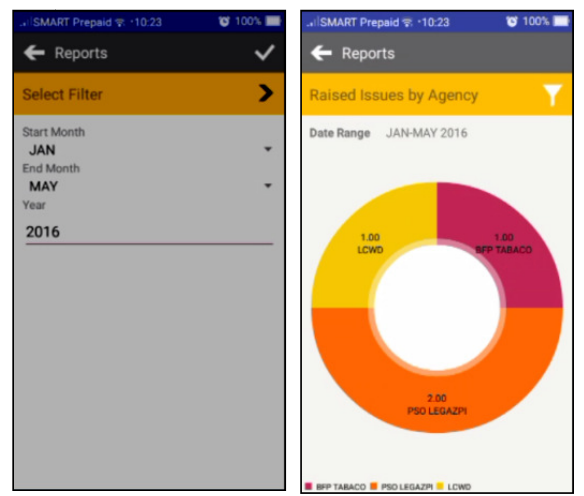

Figure 12. Report - Raised Issues by Agency

Raised Issues by Agency shows the total summary of issues categorized by agencies. This can be filtered out by start month to end month and year. This provides an statistics on which agencies are getting/receiving the most number of issues/concerns.

\section{Agency Respond Performance}
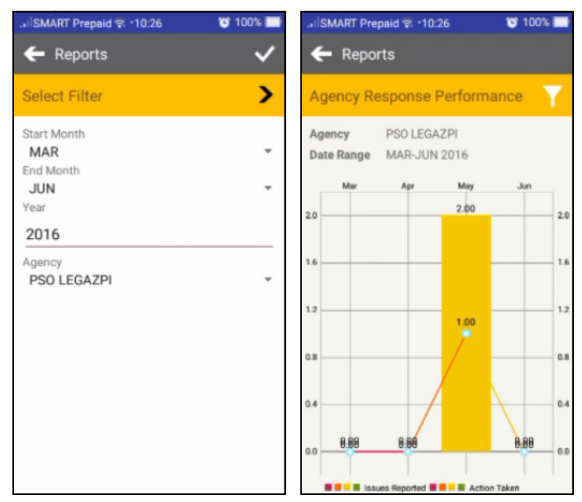

Figure 13. Report - Agency Respond Performance

This report returns the agency's performance in responding to posts. The report is filtered by start month-to-end month, year and by agency. It reflects the total number of issues/concerns raised represented by bar chart and the total resolved posts represented by a line graph. This gives an idea on how the agency performed in dealing with problems. The key here is, it reflects the overall performance of an agency in relation to giving resolution to posts initiated by users. 


\section{Unresolved Issues By Agency}

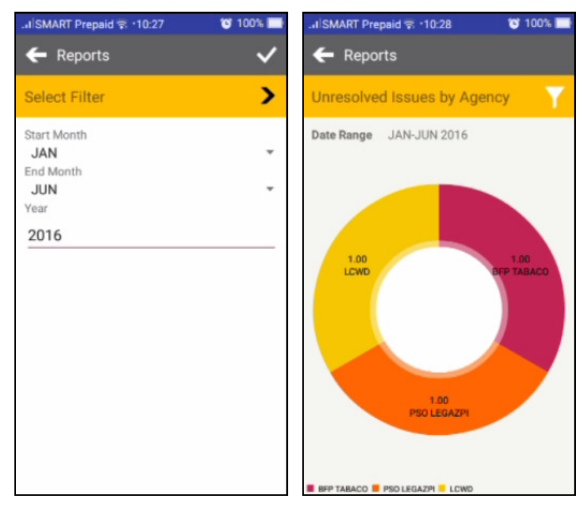

Figure 13. Report - Unresolved issues by Agency

This report shows the summary of unresolved issues by agencies. The data can be filtered by start month-to-end month and by year. Basically, when an agency is listed here with higher total, this means that the agency is not performing well and can be assumed that it failed to resolve any issues raised to them.

These features of the application found value on the data gathered from the respondents and use it to generate certain statistical data with the purpose of evaluating the job performance of agencies. By analyzing the data gathered, an evaluation or assessment tool has been made up and a forecast of possible occurrences can be extracted for future planning.

\section{Conclusions}

Bridging communication between the constituent and the concerned agency is the main goal of the study. It seeks to provide ways on how a certain concern can be brought forward directly to intended agencies. This paved way to a better agency response; a better understanding of common concerns raised; and birth of an active, concerned, and vigilant community.

There are few items that the authors wish to incorporate in this study that can be used by future researchers in order to improve this research. These are:

\section{Categorized Post}

There should be a way in classifying or categorizing where a certain post belongs. This will give detailed statistics on the data that can be analyzed from ALERRT system which can be used by the agency in implementing proper planning in responding to such concerns.

\section{ALERRT Web}

This is a web version of ALERRT to reach other users who do not have mobile devices and also to provide multiple ways on interacting to ALERRT system.

Lastly, below are the several researches that the authors wish to accomplish in the future. These are systems that can be connected to ALERRT to provide more information and public service to its users. 


\section{Flood Control System}

This is using an arduino device that automatically feeds data to ALERRT system to notify which bridges/highways/rivers are flooded.

\section{Fire Control System}

Using the ALERRT System, this envisions to automatically communicate with any Fire Department/Stations whenever fire happens to any establishment. Using an arduino device, this will prompt the department of any fire occurrences that need immediate attention.

\section{ACKNOWLEDGEMENTS}

This research paper is will not be possible without the help and support of our family.

Thank you also to all the UC-CATC MIT family for this endeavour and most of all to Almighty God for His guidance. To God be all the glory.

\section{REFERENCES}

[1] Fajardo, Jovilyn Therese, et.al (2010, June). A Mobile Disaster Management System Using the Android Technology. Retrieved from citeseerx.ist.psu.edu/viewdoc/ doi=10.1.1.458.3601

[2] K Nakajima, et. al. (2016, February). A web-based incident reporting system and Multidisciplinary collaborative projects for patient safety in a Japanese hospital. Downloaded from http://qualitysafety.bmj.com/.

[3] Asif S. Tamboli, et.al (2013, February). Incident Reporting System Using GIS. Retrieved from www.estij.org/papers/vol3no12013/10vol3no1.pdf.

[4] Eguchi, R. (2008, October). The Application of Remote Sensing Technologies for Disaster Management. Retrieved from www.iitk.ac.in/nicee/wcee/article/14_K004.pdf.

[5] Yang,C. et. al.(2010, December). Use of Mobile Phones in an Emergency Reporting system for infectious disease surveillance after the Sichuan earthquake in China. Retrieved from https://depts.washington.edu/einet/symposium/PRC031210.pdf.

[6] Barbeau,Sean et.al(2007, February). Wireless Emergency-Reporting System. Retrieved from www.research.usf.edu/absolute-news/templates $/ \mathrm{a}=2513 \& \mathrm{z}=1$.

[7] Gupta, Preeti, et. al (2011, November). Disaster Management in Flash Floods in Leh: A Case Study. Retrieved from www.ifrc.org/Global/Publications/disasters/dref/cs-India.pdf.

[8] Dong, Chuqing (2015, July). Social Media in Public Health Organizations: A Case Study of Social Media Use in the Minnesota Department of Health. Retrieved from http://www.freefullpdf.com/\#gsc.tab=0\&gsc.q=social\%20media\&gsc.sort=\&gsc.ref

[9] Owen, Daniel (2013, May). Citizen Photojournalism: Motivations for Photographing a Natural Disaster and Sharing the Photos on the Web". Retrieved from https://etd.ohiolink.edu/rws_etd/document/get/akron1362739905/inline

[10] Yunus Emre Aydin (2006, May). Web Based Multi-Participant Spatial Data Entry in Crime Mapping". Retrieved from https://etd.lib.metu.edu.tr/upload/12607250/index.pdf

[11] http://www.merkleinc.com/what-we-do/data-analytics/data-solutions/data-optimization\#.Vyox9tJ96t8 


\section{AUTHORS}

Elmer C. Figuracion is an IT Professional, an Instructor, and a freelance software developer. He finished his Bachelor's degree in Computer Science at Polytechnic Institute of Tabaco and is now taking Master in Information Technology at the University of Cordilleras, Baguio City.

Thelma D. Palaoag is a graduate of Doctor in Information Technology at the University of the Cordilleras. She is currently a faculty of the College of Information Technology and Computer Science of the same university.

Dennis Ignacio is a BSIT graduate of University of Nueva Caceres, Naga City. He is currently an IT Instructor at La Consolacion College of Daet and also a student of University of the Cordilleras taking his Master in Information Technology.

Mary Jane Doblon holds her BSCS degree at the University of Caceres, Naga City. She is an IT Instructor at La Consolacion College of Daet and likewise a student of University of the Cordilleras taking up Master in Information Technology.
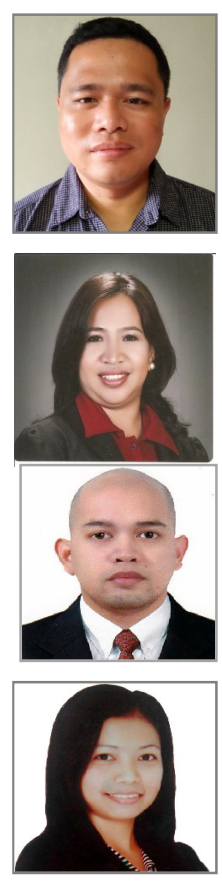